\title{
Cognitive personality schemes in college students
}

Rocio Tron Álvarez, Xochitl Karina Torres Beltrán \& María Cristina Bravo González Iztacala Higher Studies Faculty

From the cognitive behavioral perspective, the personality is based on the concept of cognitive schemes and controlling beliefs, which state the instructions that guide the center, direction and daily life qualities, as also the special contingencies (Beck Freeman and Davis 1995). Therefore, they can be translated to a group of individual characteristics stable in time, reason why the evaluation of this... has been consolidated as one of the more important ones to try to characterize groups of people with features in common, particularly in the organizational and educational ambits, where it has been tried to stablish a profile that allows to explain the desirable characteristics in a person.

Objective. To describe the cognitive personality schemes in students from the National Autonomous University of Mexico.(UNAM).

\section{METHOD}

Participants. Our sample of $662(442$ women and 233 men) students from the National Autonomous University of Mexico was obtained through a nonprobabilistic sampling. The total amount was gathered from six different departments.

Instrument. The Personality Belief Questionnaire (PBR), a 126-item assessment instrument that gathers the scales for the different personality cognitive schemes (Avoidance, Dependency, Passive-Aggressive, Obsessive-compulsive, Antisocial, Narcissistic, Histrionic, Schizoid and Paranoid).
Procedure. The questionnaire was applied to a group of students from six different UNAM Departments. Students were explained the purpose of the study and their cooperation was requested, but not without pointing out that their participation should be totally voluntary and if wanted, they could choose not to answer the questionnaire. In case they choose to participate, it was ensured to them that the information gathered would remain anonymous.

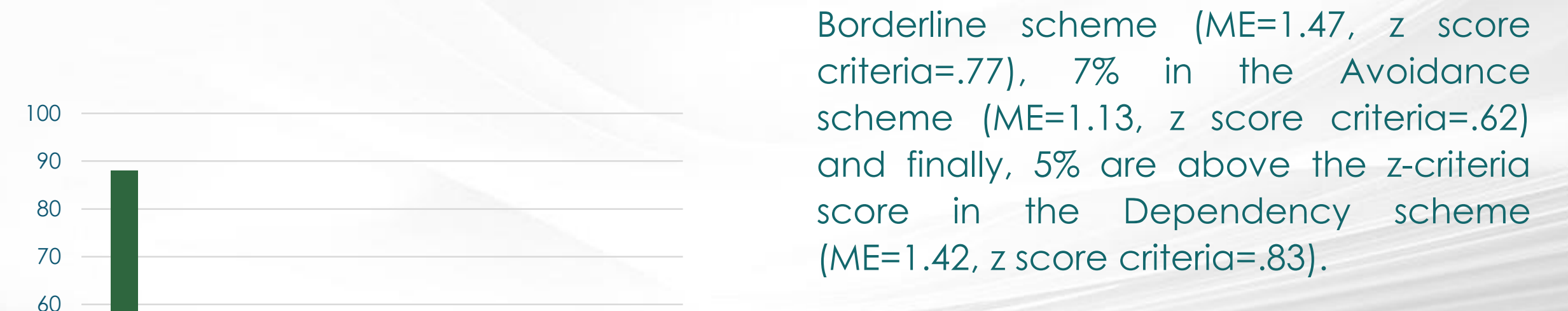

Based on the total sample, and as it can be seen in Graphic 1, $88 \%$ of the students exceed by far the score criteria for people with psychiatric diagnosis on the Antisocial scheme, with a z-value average of 1.85, way higher than the $z$ value criteria of .31 . With this same criteria value, in the Obsessive-compulsive scheme $40 \%$ exceed that score, with an average $\mathrm{z}$ value of 1.09 , in the Narcissis scheme $32 \% \quad(M E=2.07, \quad z$ criteria score $=1.10$ ), $28 \%$ in the Paranoid scheme $(\mathrm{ME}=1.44$, $\mathrm{z}$ score criteria $=.51), 9 \%$ in the Borderline scheme (ME=1.47, $z$ score criteria $=.77), 7 \%$ in the Avoidance $(\mathrm{ME}=1.42$, $\mathrm{z}$ score criteria $=.83$ )

\section{DISCUSSION}

The most striking element from the results is the large amount of students with a high score at the antisocial scheme. The main strategies correspond to the manipulation, deceit, combativeness, predation and exploitation (Beck, et al., 2005). This result could be related to the current Mexican social context, with high levels of insecurity, violence and intolerance, where the concept "survival of the fittest" seems to apply, and the most important thing, the increasing indifference to each other and the decreasing solidary behavior. That's why the strategies previously described could be used to face a difficult daily life.

\section{RESULTS}

Results. The instrument allows us the get $z$ scores for each scheme, which can be compared to the $z$ value criteria for patients with a psychiatric diagnosis (except for the Passive-aggressive, Histrionic and Schizoid schemes).

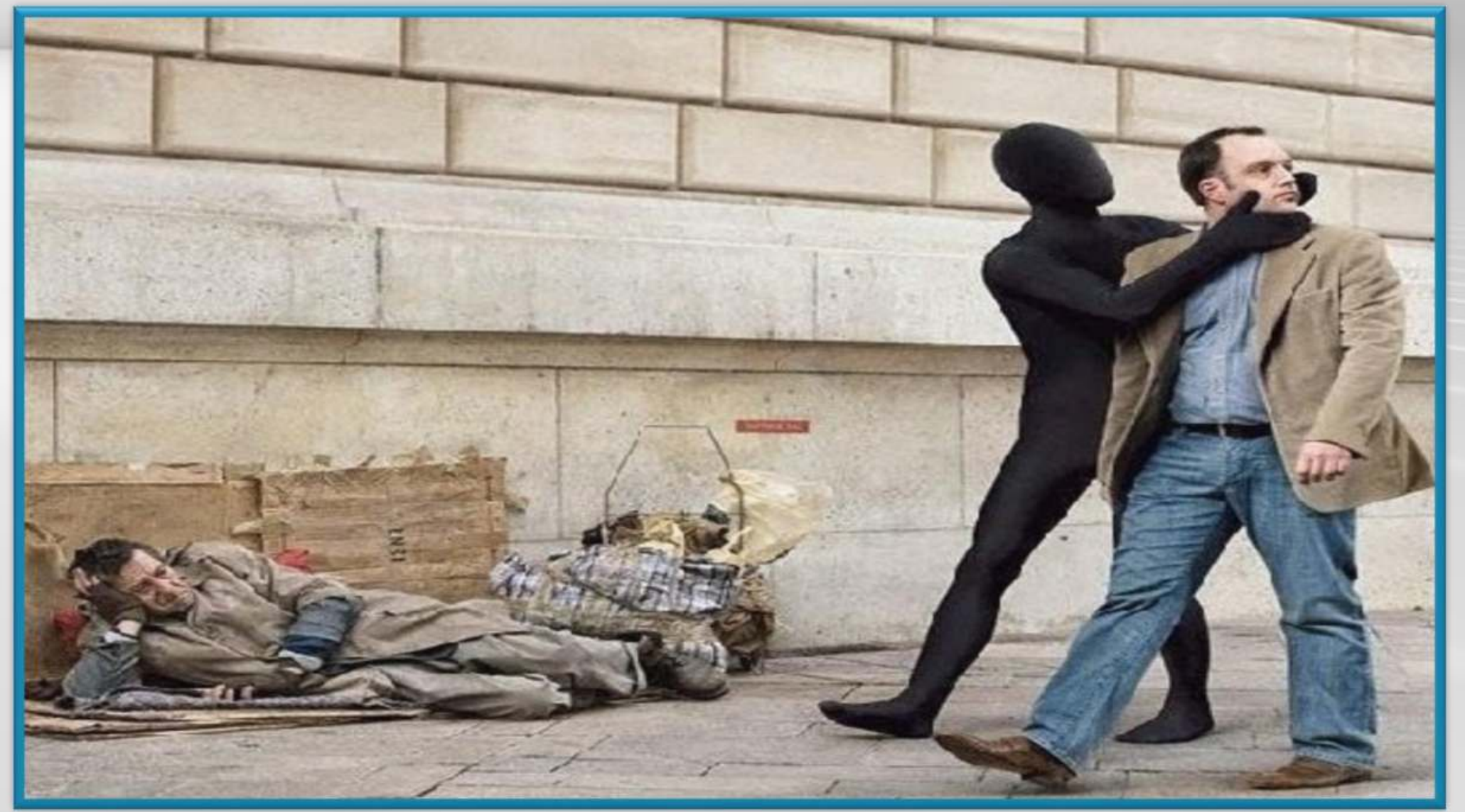

